\title{
The effect of child abuse on children's psychological health
}

\author{
Kingsley Nyarko ${ }^{1}$, Christopher M. Amissah ${ }^{1}$, Prince Addai ${ }^{2}$, Believe Quaqoo Dedzo $^{3}$ \\ ${ }^{1}$ University of Ghana, Psychology Department, P. O. Box LG 84, Legon \\ ${ }^{2}$ University of Ghana, Distance Education, Kumasi Center, P. O. Box 838, Adum, Kumasi \\ ${ }^{3}$ University of Ghana, Department of Organizational and Human Resource Management, P. O. Box LG 78, Legon
}

\section{Email address:}

kingpong73@yahoo.com (K. Nyarko), chrismartinamissah@gmail.com (C. M. Amissah), princegandy90@yahoo.com (P. Addai) behorsh28@gmail.com (B. Q. Dedzo)

\section{To cite this article:}

Kingsley Nyarko, Christopher M. Amissah, Prince Addai, Believe Quaqoo Dedzo. The Effect of Child Abuse on Children's Psychological Health. Psychology and Behavioral Sciences. Vol. 3, No. 4, 2014, pp. 105-112. doi: 10.11648/j.pbs.20140304.11

\begin{abstract}
The study examines the impact of child abuse on children's psychological health. Child abuse was defined as physical and psychological abuses against children whilst psychological health was defined in relation to children's selfesteem, depression, and anxiety. 109 children were purposively sampled to partake in the study. The sample consisted of both males $(n=68)$ and females $(n=41)$ from diverse socio-economic backgrounds, whose ages were from 9 to 18 years. The research design used was a survey, and the independent samples t-test was used to analyze the data. Some of the participants have histories of abusive treatment $(n=57)$ whilst others were without any such history ( $n=68)$. Among those who had suffered abusive treatment, 36 suffered physical abuse and 21 suffered psychological abuse. Standardized measures were used to rate each participant's level of depression and anxiety. The analyses of the data show that both physical and psychological abuses lead to a significant increase in children's depression and anxiety. These findings are discussed with reference to existing psychological literature and theories.
\end{abstract}

Keywords: Child Abuse, Physical Abuse, Psychological Abuse, Psychological Health, Self-Esteem, Depression, Anxiety

\section{Introduction}

Childhood life experiences are known to have a strong link with people's psychological wellbeing (Cox, Kotch \& Everson, 2003). Negative childhood experiences usually predict poor psychosocial and physical functioning even in adulthood (MacMillan, Fleming, Streiner, Lin, Boyle, Jamieson, Duku, Walsh, Wong, \& Beardslee, 2001). Child abuse is the ill treatment of children by parents, guardians, or significant others who usually share some kind of relationship with the child. Child abuse may be physical, psychological, or sexual. Physical child abuse involves the direct infliction of pains and injuries unto a child. Psychological abuse, on the other hand, is the coercive or aversive acts intended to produce emotional harm or threat of harm. In contrast to physical abuse, these coercive behaviors are not directed toward the target's bodily integrity, but are instead directed at the recipient's sense of self (Murphy \& Cascardi, 1999). Psychological abuse is often intended to diminish another person's self-esteem and mental well-being whereas physical abuse leads the victim with some form of physical pain or injury. Sexual child abuse refers to any unwanted or coerced or tricked sexual interaction with a child. Such unwanted sexual interaction may include kissing, fondling, oral sex, anal sex, sodomy and intercourse (Peters, Wyatt, \& Finkelhor, 1986).

Earlier studies have shown limited focus on child physical abuse, or not specifying if the child maltreatment was sexual, physical, emotional, or neglect. Besides child physical abuse, it is important to study psychological child abuse. Psychological child abuse refers to acts such as ridiculing a child, threatening to harm a child, and other emotional abuses (McGuigan \& Pratt, 2001). Psychological child abuse may not cause immediate physical harm to the child but may have long-term mental health consequences that are just as damaging as physical abuse or neglect (MacMillan et al., 2001;Widom, 2000). Child neglect is an important type of child maltreatment that has received little attention in the child maltreatment research. Child neglect includes lack of supervision, medical neglect, failure to provide food or clothing, inadequate shelter, desertion, 
abandonment, and other physical neglect (McGuigan \& Pratt, 2001). Child neglect is the most frequently occurring type of child maltreatment (Erickson, \& Egeland, 2002). Few studies have examined the relative effects of the various forms of child abuse on children's psychological wellbeing (Dubowitz, Pitts, \& Black, 2004; Hartley, 2002; New Jersey Division of Youth and Family Services, 2006).

Child abuse is not only deleterious to the health and well-being of adult victims, but also has implications for the development of children (MacMillan et al., 2001). Apart from the physical pains and emotional trauma children suffer in abusive environments, there are a host of other psychological ill effects of child abuse which might go unnoticed. Psychologically abused children have been shown to have lower self-efficacy, higher depression, lower self-esteem, and increased risk of posttraumatic stress disorders than non-abused children (Street \& Arias, 2001, Hartley, 2002). Studies have shown that being psychologically abused during childhood is predictive of illegal drug use, negative health perceptions, and cognitive impairment even after controlling for physical violence victimization (Straight, Harper, \& Arias, 2003). Victims of child psychological aggression are also more likely than others to report physical health problems such as arthritis, chronic pain, migraine, sexually transmitted diseases, and stomach ulcers (Coker, Smith, Bethee, King, \& McKeown, 2000; Crouch, Milner, Skowronski, Farc, Irwin, \& Neese, 2010; Street \& Arias, 2001).

One of the etiological factors for child depression and anxiety disorders is insecure attachment of the child to its caregivers which is related to psychological child abuse or neglect. Bowlby's attachment theory $(1969,1973,1989)$ assumes that children have an evolutionary tendencies to behave in ways that enhance proximity to their caregivers. Children are biologically equipped with verbal and nonverbal behaviours that elicit certain instinctive nurturing responses from their caregivers. The sensitivity of the caregiver's response determines the security of the child in the relationship. Pelaez-Nogueras, Gewirtzk, Field, and Cigales, (1996) confirmed that touch from caregiver's elicit positive emotions and attention from almost all children. Attachment involves hugging, cuddling, and caresses that children naturally receive from their primary caregivers. The early attachment experiences make the child form an "internal working model" of the self (Ainsworth, Blehan, Waters, \& Wall, 1978). Insecure early attachment experiences lead individuals to form internal working models that interfere with other relationships. Thus, children's anxious behaviour may be related to their perception and experience of the availability and accessibility of the caretaker in the role of comforter and protector. The absence of secure attachment elicits feelings of neglect which, in this context, is a form of psychological abuse.

Two types of insecure attachment have been described: (1) anxious-avoidant attachment - in which the individual is comfortable without intimate relationships and therefore tends to reject them, and (2) anxious-ambivalent attachment - in which the individual is uncomfortable without intimate relationships and hence becomes overinvolved in these relationships (Ainsworth et al., 1978). The quality of attachment plays a vital role in an individual's development, as it affects the degree to which an individual can adapt to deviation from normal development without the development of psychopathology (Rosenstein \& Horowitz, 1996). In fact, it has been proposed that the early development of insecure attachment does not produce pathology, but rather increases one's vulnerability to disorder, particularly when combined with other risk factors, such as family dysfunction and abuses (Rosenstein \& Horowitz, 1996).

It has been postulated that abusive parents have more unrealistic and rigid expectations for children, and that they perceive their children's behavior more negatively than do outside observers (Chang, Theodore, Martin, \& Runyan, 2008). Often time, these parents attribute hostile intent to their children's behavior, and easily become angered which might lead to coercive parenting styles or abuse of their children (Slep \& O'Leary, 2001). In addition, children could be harmed indirectly via the stress in the home. Margolin and Gordis (2003) revealed that the combination of financial and parenting stress potentiated the association between marital aggression and abusive parenting behaviors. Other researchers have also reported that exposure to negative forms of marital conflict is linked with children's aggressiveness, emotional distress, and risk of adjustment problems (Chang et al., 2008).

Although the deleterious effects of child abuse are well documented, certain inconsistencies remain. Researchers have reported that a significant number of abused children develop into emotionally maladjusted adults (MacMillan, et al., 2001; Widom, 2000). Cox, Kotch, and Everson (2003) maintained that pathological parental attitudes and behaviors influence children's emotional and psychological development. Rodriguez (2010) added that psychological processes play a significant role in the way an individual perceives and organizes his or her understanding of the world. The perceiver is not a passive observer in the face of ongoing events but an active participant in selecting and synthesizing stimuli.

Maltreated children experience anxiety, feelings of isolation and stigma, poor self-esteem (Crouch et al., 2010; Daigneault, Hebert, \& McDuff, 2009), difficulty in trusting others, relationship problems (Widom, 2000), and poor self-esteem and negative self-concepts (MacMillan, et al., 2001). Other researchers mentioned that the effects of child abuse include deviant self-concept, troubled socialization with peers, difficulty trusting others, low self-esteem, and decreased effectiveness in comprehending complex roles (MacMillan, et al., 2001; Chang et al., 2008; Cox, Kotch \& Everson, 2003). Erickson and Egeland (1987) reported that abuse is inherently tied to a lack of support and nurturance which directly impacts on the child's sense of self. The abused child learns from his or her experiences that their feelings are unimportant and not worthwhile which result in 
low self-esteem and an impairment of a cohesive sense of identity (MacMillan et al., 2001). These deficits are theorized to relate directly to problems in the interpersonal adjustment of abuse victims as children and adults (Milner, 2003).

Child abuse has also been associated with the development and diagnosis of post-traumatic stress disorder (PTSD) (Zlotnick, Mattia, \& Zimmerman, 2001). In a study examining adults with child sexual abuse histories, Rodriguez, Ryan, Rowan and Foy (2006) reported that 72\% of their sample met full DSM-III criteria for current PTSD, while $86 \%$ met criteria for lifetime PTSD. Rowan, Foy, Rodriguez, \& Ryan (2004) found that of 47 adults who disclosed histories of childhood sexual abuse, $69 \%$ met full DSM-III criteria for PTSD, while another 19\% met criteria for partial PTSD. Further, child sexual abuse has also been associated with mood disorders, anxiety disorders, conduct disorders, substance abuse disorders, suicidal behaviors and with borderline personality disorder, chronic headaches, maladaptive sexual behavior, irritable bowel syndrome, dissociative behaviors, depression, alcoholism, panic disorder, and social phobia (Rodriguez et al., 2006; Zlotnick, et al. 2001).

This study seeks to expand the approach of investigation by including both physical and psychological forms of child abuse within the Ghanaian context. Most researches on child abuse have shown narrowed interest in the physical and sexual dimensions of child abuse (e.g., Crouch et al., 2010; Milner, 2003; Rodriguez et al., 2006; Zlotnick, et al. 2001). Until now, no study has yet attempted to offer comprehensive analyses on the effect of both physical and psychological child abuse on children's psychological health.

The current study therefore examines the effects of both the physical and psychological forms of child abuse on children's psychological health within the framework of Bowlby's attachment theory. Based on the above reviewed literature and the stated aims and objectives, the following hypotheses were proposed: 1) Physically abused children are more likely to suffer lower self-esteem than non-abused children, 2) Psychologically abused children are more likely to suffer lower self-esteem than non-abused children, 3) Physically abused children are more likely to be more depressed than non-abused children, 4) Psychologically abused children are more likely to be more depressed as compared to non-abused children, 5) Physically abused children are more likely to suffer greater anxiety as compared to non-abused children, 6) Psychologically abused children are more likely to suffer greater anxiety than their non-abused counterpart.

\section{Method}

\subsection{Population and Sample}

It has been suggested that it is difficult to rely on retrospective accounts as valid reports of childhood experiences, particularly when the experiences are highly personal in nature. It is probably that subjects deny, distort and/or unconsciously forget painful experiences when responding to questionnaires at later years of the occurrence (Belsky, 1993; Paulhus, 1991). Based on this difficulty, the researcher chose to investigate the effect of child abuse from the perspective of children in their present situation. Children in Nungua Community of the Ledzokuku-Krowor municipality of the Greater Accra Region of Ghana constituted the population for the study.

The population had two subdivisions: The first category was children with abusive treatment and the second was children without abusive treatment. Abusive treatment was classified into physical and psychological abuse. One hundred and nine (109) children participated in the study. Out of this number, 33\% $(n=36)$ had suffered physical abuse, $19.3 \%(n=21)$ had suffered psychological abuse, and $47.7 \%(n=52)$ had not suffered any form of abuse. Males constituted $62.4 \%(n=68)$ whilst females constituted $37.6 \%(n=41)$. The ages of the participants ranged from 9 years to 18 years. The mean age was 13.84 with a standard deviation of 2.348 .

Among the participants, $85.3 \%(n=93)$ were enrolled in school, $6.4 \%(n=7)$ had dropped out of school, and $8.3 \%$ $(\mathrm{n}=9)$ had never been to school. With regard to religious affiliation, $80.7 \%$ of the children were Christians $(n=88)$, $15.6 \%$ were Muslims $(n=17)$, and the remaining $3.7 \%(n=$ 4) did not belong to any religious group. In terms of their home environment, $38.5 \%$ of the children $(n=42)$ were living with both parents, $22.9 \%(n=25)$ were living with only one of their parents, $35.8 \%$ were living with guardians $(n=39)$, and $2.8 \%(n=3)$ were homeless.

\subsection{Sampling Technique}

The purposive sampling technique was employed for the study. The use of this technique became relevant to the study due to the fact that the researchers needed to obtain a cross-section of the children population who were suffering from either physical or psychological abuse. Based on the fact that abused children are only identifiable after careful search, the researchers made contact with relevant state institutions in order to obtain the identities and locations of children with histories of abuse.

\subsection{Research Design}

The survey research design was used in the study. This was appropriate because the researcher relied heavily on self-report of children's judgment of parental treatment and their own psychological feelings in terms of self-esteem, depression and anxiety.

\subsection{Measures}

Questionnaires were used for the data collection. Each questionnaire comprised three main sections. The first section gathered demographic data of the respondents such as gender, age, and educational level. The second section measured the extent of physical and psychological abuse of 
children. The third section measured the psychological effect of child abuse.

\subsubsection{Child Abuse Scale}

A modification of the Assessing Environments (AE) - III (Berger \& Knutson, 1984) was used to measure participants' recall of past physical and psychological abuse and neglect. The physical dimension of child abuse was measured using the Physical Punishment scale from the AE-III. This scale is made up of 11 items and it has a Cronbach alpha of .83 (Gauthier, Stollak, Messi \& Aronoff, 1996). Two of the items on the scale are "My mother/father used physical discipline with me" and "My mother/father used to spank me." Secondly, the Parental Neglect scale of the AE-III was used to measure the psychological dimension of child abuse. The scale has 8 items and the Cronbach alpha is .76 (Gauthier et al. 1996). A sampled item of this scale is "My mother/father was easy-going and relaxed with me, yet interested and committed to my welfare and development." The original AE-III has been revised by rewording some of the items to make them easier to understand and again the response pattern was changed from true-false to a 4- point Likert scale (Gauthier et al. 1996).

\subsubsection{Psychological Wellbeing Scale}

The psychological effect of child abuse was measured in terms of the child's self-esteem, depression, and anxiety. The self-esteem of the children was assessed with the Rosenberg Self-esteem Scale (Rosenberg, 1965). The Rosenberg Self-esteem scale is a 10-item self-report scale designed to measure global self-esteem. Some items on the scale are "I feel that I have a number of good qualities," "I feel I do not have much to be proud of," and "At times I think I am no good at all. The reliability of the scale is known to range from .79 to .86 .

Secondly, depression was measured with the Center for Epidemiological Studies Depression Scale for Children (CES-DC). The scale is a 20 item inventory with a reliability coefficient of 0.72 (Weissman, Orvaschel \& Padian, 1980). The CES-DC was used to assess the depression level of the participants. Sampled items from this scale are "I was bothered by things that usually don't bother me" and "I did not feel like eating, I wasn't very hungry".

Finally, anxiety was assessed with the Spence Children's Anxiety Scale. This measure was developed by Spence (1994). It consists of 44 items of which 38 reflect specific symptoms of anxiety and 6 relate to positive, filler items to reduce negative response bias. Some of the questions on the scale are "I worry about things" and I am scared of the dark." The measure has a reliability coefficient of 0.93 .

\subsection{Scoring}

Items in the Physical Punishment scale, the Parental Neglect scale and Rosenberg Self-Esteem scale were all scored on a 5- point Likert scale. The responses range from
"Strongly Agree" (with 5 marks), "Agree" (4 marks), "Neutral" (3 marks), "Disagree" (2 marks) and "Strongly Disagree" (1). Items 1, 3, 6 and 7 of the Parental Neglect scale and items 3, 5, 7, 8, and 9 of the Rosenberg SelfEsteem scale were reverse scored in which case a "Strongly Agree" response attracts 1 mark, "Agree" with 2 marks, "Neutral" with 3 marks, "Disagree" with 4 marks, and "Strongly Disagree" with 5 marks.

The items on the Center for Epidemiological Studies Depression Scale for Children (CES-DC) had "Not at all," "A little," "Some," and "A lot" responses. A "Not at all" response was scored $0, A$ "little" response was scored 1, A "Some" response was scored 2, and " $A$ lot" response was scored 3. However, items on the Spence Children's Anxiety Scale of the questionnaire had "Never," "Sometimes," "Often," and "Always" responses. A "Never" response was scored 0, a "Sometime"” response was scored 1, an "Often" response was scored 2 and an "Always" response was scored 3 .

\subsection{Procedure for Data Collection}

The researchers obtained an introductory letter from the Psychology Department of the University of Ghana. The researchers visited the Domestic Violence Victims' Support Unit (DOVVSU) of the Ghana Police Service (Nungua Division). The introductory letter was presented to the administrators of DOVVSU as a means of introducing the researchers and their assistants and indicating the purpose of the research. The researchers obtained the list and location of children with abusive histories. They then did a follow up trace on the children. After locating them, the researchers administered the research questionnaires to them. Similarly, the researcher identified and administered questionnaires to children in the Nungua community who had not suffered any form of abuse. Prior to the administration of the questionnaires, the researchers provided information on the essence of the research to the participants in order to obtain their consent. After their consent had been solicited, the participants were provided with the questionnaires and provided guidance to complete them. All participants were assured of confidentiality in the responses they offered.

\subsection{Data Analysis}

The data analysis was done by using both descriptive and inferential statistics. Descriptive statistics was used to analyze the demographic variables used in the study. It was used to determine the frequency distributions, means, and standard deviations of the variables. These variables include, age, gender, educational status, family structure, religious affiliation. Also, test statistics (independent t-test) was used to address all the hypotheses. This was because the researchers wanted to find out the differences in the means of children who have experienced child abuse (physical \& psychological) in relation to their psychological health (self-esteem, depression, \& anxiety). 


\section{Results}

Mean differences of physically and psychologically abused children and their self-esteem.

Table 1. The Effect of Child Abuse on Children's Self-Esteem

\begin{tabular}{l|cccccc}
\hline Child-Abuse & $\boldsymbol{n}$ & Mean & SD & $\boldsymbol{d f}$ & $\boldsymbol{t}$ & sig. \\
\hline Physical & & & & & & \\
Abused & 36 & 29.36 & 6.50 & 86 & -2.46 & .016 \\
Non-Abused & 52 & 33.00 & 7.06 & & & \\
Psychological & & & & & & \\
Abused & 21 & 28.52 & 8.55 & 71 & -2.31 & .024 \\
Non-Abused & 52 & 33.00 & 7.06 & & & \\
\hline
\end{tabular}

$\mathrm{P}<0.05$

The result in table 1 reveals that physical child abuse had a significant negative impact on children's self-esteem $\left(t_{(86)}\right.$ $=-2.46, p<.05)$. Physically abused children has lower selfesteem $(\mathrm{M}=29.36, \mathrm{SD}=6.503)$ than non-abused children $(\mathrm{M}=33.00, \mathrm{SD}=7.06)$. Similarly, psychological child abuse also has a significant negative effect on children's self-esteem $\left(t_{(71)}=-2.31, p<.05\right)$. The self-esteem of children who have suffered psychological abuse $(\mathrm{M}=28.52$, $\mathrm{SD}=8.56)$ is significantly lower than the self-esteem of children who suffered no abuse $(\mathrm{M}=33.00, \mathrm{SD}=7.06)$.

Mean differences of physically and psychologically abused children and their depression

Table 2. The Effect of Child Abuse on Depression among Children

\begin{tabular}{lcccccc}
\hline Child Abuse & $\boldsymbol{n}$ & Mean & $\boldsymbol{S D}$ & $\boldsymbol{D f}$ & $\boldsymbol{t}$ & sig. \\
\hline Physical & & & & & & \\
Abused & 36 & 54.81 & 8.65 & 86 & 4.17 & .000 \\
Non-Abused & 52 & 47.29 & 8.08 & & & \\
Psychological & & & & & & \\
Abused & 21 & 54.81 & 9.37 & 71 & 3.44 & .001 \\
Non-Abused & 52 & 47.29 & 8.08 & & & \\
\hline
\end{tabular}

$\mathrm{P}<0.05$

Table 2 above shows that physical child abuse has a significant influence on depression among children $\left(t_{(86)}=\right.$ $4.17, p<.01)$. Depression is higher among children who have suffered physical abuse $(\mathrm{M}=54.81, \mathrm{SD}=8.65)$ than children who have not suffered any abuse $(\mathrm{M}=47.29, \mathrm{SD}$ $=8.08)$. Psychological child abuse also has a significant effect on depression among children $\left(t_{(71)}=3.44, p<.01\right)$. The rate of depression is higher among children who have been psychologically abused $(\mathrm{M}=54.81, \mathrm{SD}=9.37)$ than children who have not been abused $(\mathrm{M}=47.29, \mathrm{SD}=8.08)$.

Mean differences of physically and psychologically abused children and their anxiety
Table 3. The Effect of Child Abuse on Anxiety among Children

\begin{tabular}{lcccccc}
\hline Child-Abuse & $\boldsymbol{n}$ & Mean & $\boldsymbol{S D}$ & $\boldsymbol{d} \boldsymbol{f}$ & $\boldsymbol{t}$ & $\boldsymbol{s i g}$. \\
\hline Physical & & & & & & \\
Abused & 36 & 121.97 & 12.82 & 86 & 2.32 & .023 \\
Non-Abused & 52 & 114.06 & 17.45 & & & \\
Psychological & & & & & & \\
Abused & 21 & 123.24 & 17.81 & 71 & 2.02 & .047 \\
Non-Abused & 52 & 114.06 & 17.45 & & & \\
\hline
\end{tabular}

$\mathrm{P}<0.05$

Table 3 above shows that physical child abuse has a significant impact on anxiety among children $\left(t_{(86)}=2.32\right.$, $p<.05)$. Children who have been physically abused appear more anxious $(\mathrm{M}=121.97, \mathrm{SD}=12.818)$ compared to children who have not been abused $(\mathrm{M}=114.06, \mathrm{SD}=$ 17.45). Psychological abuse also significantly affects the anxiety level of children $\left(t_{(71)}=2.02, p<.05\right)$. Children who have been psychologically abused are found to be more anxious $(\mathrm{M}=123.24, \mathrm{SD}=17.81)$ than children who have not been abused $(\mathrm{M}=114.06, \mathrm{SD}=17.45)$.

\section{Discussion and Recommendations}

\subsection{Discussion}

Child abuse is one of the most commonly identified evils in society. According to the U.S. Advisory Board on Child Abuse and Neglect (1990), beating children, chronically belittling them, using them for sexual gratification, and depriving them of the basic necessities of life are repellent acts and cannot be permitted in a civilized society. The psychological problems associated with child abuse are well documented in the literature across many countries. This study investigated the extent to which abused children in Ghana suffer from depression, anxiety and low selfesteem. Child abuse is conceptualized in this study as physical and psychological. Physical abuse involves the physical harm inflicted upon children by parents or significant others whilst psychological abuse implies the neglect of the social, emotional and psychological needs of children. The results of the study reveal that both physical and psychological child abuses reduce the self-esteem of children and increase their depression and anxiety.

In relation to the first and second hypotheses, we observed that physically abused and psychologically abused children suffer lower self-esteem than non-abused children. Beating children, chronically belittling them, or depriving them of their basic needs may make children experience lower sense of self-worth or perceive life as meaningless. As earlier studies have established, child abuse usually results in poor self-esteem and negative selfconcepts among children. Physical child abuse makes children develop deviant self-concept, troubled socialization with peers, difficulty trusting others, low selfesteem, and decreased effectiveness in comprehending 
complex roles (Chang et al., 2008; Cox, Kotch \& Everson, 2003; MacMillan, et al., 2001). Erickson and Egeland (1987) have reported that abuse is inherently tied to a lack of support and nurturance which directly impacts on the child's sense of self.

Psychologically abused children may also suffer lower self-esteem because neglecting the social, emotional, and psychological needs of children has the likelihood of making them develop distorted views and lead them to negative evaluation of themselves. In such circumstance, MacMillan et al. (2001) explained that the abused child learns from his or her experiences that their feelings are unimportant and not worthwhile. This results in low selfesteem and an impairment of a cohesive sense of identity. These deficits are theorized to relate directly to problems in the interpersonal adjustment of abuse victims whether as children or adults.

According to Bowlby's attachment theory (1969, 1973, 1989), children have an evolutionary tendency to behave in ways that enhances proximity or attachment to their caregivers and failure or disruption in the process results in psychological problems such as low self-esteem. Our finding confirms that neglect is detrimental to self-esteem. As observed in the study, children who did not suffer any form of psychological abuse in the form of neglect have higher self-esteem. However, children who suffer psychological abuse in the form of neglect suffered lower self-esteem. This observation is consistent with the view of Pelaez-Nogueras et al. (1996) that touch from caregiver's elicit positive emotions and attention from almost all children in a way that make them feel good about themselves and guarantee them with a sense of identity. In the same way, the absence of touch from, or secure attachment to a caregiver has negative psychological consequences to children.

Again, in connection to the third and fourth hypotheses, it was found that physically abused and psychologically abused children are more depressed than non-abused children. This finding confirms the earlier finding by Street and Arias (2001) that children who suffer various form of abuses also suffer persistent forms of depression. Depression is known to occur more frequently among people who suffer from acute forms of stressors. Coker et al. (2000) indicated that children who live in hostile environments are usually depressed, and sometimes inactive among their peers. However, depression is believed to be more common among adult population than among children (Hartley, 2002). This implies that children become depressed when they are exposed to early stressors of life such as abuses from parents or significant others. Just as physical abuse leads to depression among children so does psychological abuse.

Whenever children are neglected socially and emotionally, they begin to develop a sense of loneliness that naturally leads them to experience feelings of depression. The evidence in this finding strengthens the assumption of Bowlby's attachment theory $(1969,1973$, \&
1989) that children have evolutionary tendencies to behave in ways that enhance proximity to their caregivers. Disruption in the attachment process makes children suffer a number of psychological problems including depression. Abuses nevertheless can be controlled to ensure healthy psychological wellbeing among children. According to Pelaez-Nogueras et al. (1996), a simple touch from caregiver's elicit positive emotions in all children in a way that make them feel good about themselves.

Finally, as regards the fifth and sixth hypotheses, the study showed that physically abused and psychologically abused children suffer greater anxiety than their non-abused counterpart. Anxiety is known as the feeling of nervousness and agitation that something unpleasant will happen. Whenever children are constantly exposed to abuses, they begin to dread being inflicted with physical pains or rejection anytime they feel or think that a hostile person is around them. According to Slep and O'Leary (2001), such children begin to attribute hostile intent to their caregivers or significant others, and easily become frightened at their presence. This makes such children live and grow in anxiety and this may be psychologically disturbing. Once an abused child develops anxiety for the hostile individual, he or she may extend the anxiety to other persons who may not necessarily be hostile to them. This fact is expressed by Cox, Kotch, and Everson (2003) who maintained that children perceive and react to certain pathological parental attitudes and behaviors in a manner that compromises their psychological wellbeing.

According to Rodriguez (2010), psychological processes play a significant role in the way the child perceives and organizes his or her understanding of the world. The child is not a passive observer in the face of ongoing events but an active participant in selecting and synthesizing stimuli. Obviously child anxiety is linked with psychological abuse of children. This observation is congruent with the conclusion of Crouch et al. (2010) that maltreated children experience anxiety and feelings of isolation. Widom (2000) had earlier also argued that children who are psychologically neglected become anxious and experience difficulty in trusting others. They also tend to suffer relationship problems. Thus psychological abuse must be seen as serious a problem as physical abuse.

This study is without limitations. It must be pointed out that the researchers' definition of child abuse was limited only to physical and psychological abuse. Although sexual child abuse appears to be an increasing phenomenon in the Ghanaian society, the researchers excluded it in their definition of child abuse on grounds of convenience. Although, the researchers were apparently aware of the need to include sexual abuse in the definition and exploration of child abuse, they failed to do so primarily due to difficulty in obtaining data on this sensitive phenomenon. Family interjections made it difficult for us to obtain the relevant data on sexual child abuse, thus its exclusion in this present study. 


\subsection{Recommendations}

Irrespective of the identified limitations, the study has produced findings upon which the following recommendations are proposed: first, given that both physical and psychological child abuses have enormous adverse influence on the psychological wellbeing of children in terms of their self-esteem, depression, and anxiety, the researchers recommend that relevant state institutions such as the Ministry of Women, Gender, and Social Protection take proactive measures to control the incidence of physical and psychological child abuse in the country. Second, whist legal policies may be used to reduce or prevent physical child abuse; education, affective training, as well as attitudinal change may be effective control measures against psychological child abuse. Third, given that Ghanaians have high sense of morality and are highly religious, the researchers also recommend the use of religious campaign and advocacy to fight against the incidence of child abuse in the Ghanaian community. This measure may be most effective based on the fact that almost every Ghanaian is affiliated to one religious group or the other. Moreover, members of the religious groups usually have high respect for their religious leaders. In this sense, any advocacy message carried by religious leaders on evils of child abuse is likely to yield positive results on their followers. Finally, parents, significant others, and care givers should be careful about their interactions with children. They need to use empirically-driven behavioural modification techniques that are proven to positively shape behaviour. Physical abuse (e.g. spanking) and psychological "torture" (e.g. ridicule) of children should give way to reinforcement, shaping, and other effective methods of changing behaviour.

\section{Conclusion}

The current study has made important contributions to our understanding of the consequence of different forms of child maltreatment. It is clearly established in this study that both physical and psychological child abuse have negative consequences on psychological health. In more specific terms, the study has revealed that physically abused and psychologically abused children suffer lower self-esteem, higher rate of depression and higher rate of anxiety compared to non-abused children. The current study thus extends the findings of earlier researchers. It also further articulates and strengthens the theoretical postulations of Bowlby $(1969,1973, \& 1989)$ that secure attachment is a necessary tool for psychological health and the lack of it results in psychological problems among children. Given all the ill effects of physical and psychological child abuse, it is necessary for state institutions, educational establishments, non-governmental organizations, and religious groups to help curb the rising incidence of child abuse in order to restore psychological health to children who are suffering abuses in different forms.

\section{References}

[1] Ainsworth, M. D. S., Blehan, M. C., Waters, E., \& Wall, S. (1978). Patterns of attachment: A psychological study of the strange situation. Hillsdale, N.J.: Erlbaum.

[2] Bowlby, J. (1969). Attachment and loss, Vol. I: Attachment. New York: Basic Books.

[3] Bowlby, J. (1973). Attachment and loss, Vol II: Separation and anxiety. New York: Basic Books.

[4] Bowlby, J. (1989). Secure attachment. New York: Basic Books.

[5] Chang, J. J., Theodore, A. D., Martin, S. L., \& Runyan,D. K. (2008). Psychological abuse between parents: Associations with child maltreatment from a populationbased sample. Child Abuse \& Neglect 32, 819-829.

[6] Coker, A. L., Smith, P. H., Bethee, L., King, M. R., \& McKeown, R. E. (2000). Physical health consequences of physical and psychological intimate partner abuse. Archives of Family Medicine, 9, 451-457.

[7] Cox, C. E., Kotch, J. B., \& Everson, M. D. (2003). A longitudinal study of modifying influences in the relationship between domestic violence and child maltreatment. Journal of Family Medicine, 18(1), 5-17.

[8] Crouch, J. L., Milner, J.S., Skowronski, J. J., Farc, M.M., Irwin, L.M., \& Neese, A. (2010). Automatic encoding of ambiguous child behavior in high and low risk for child physical abuse parents. Journal of Family Violence, 25, 7380.

[9] Dubowitz, H., Pitts, S., \& Black, M. (2004). Measurement of three major subtypes of child neglect. Child Maltreatment, 9, 344-356.

[10] Erickson, M. F., \& Egeland, B. (1987). A developmental view of the psychological consequences of maltreatment. School Psychology Review, 16(2), 156-168.

[11] Erickson, M. F., \& Egeland, B. (2002). Child neglect. In J. B. Myers, L. Berliner, J. Briere, C. T. Hendrix, C. Jenny, \& T. A. Reid (Eds.), The APSAC handbook on child maltreatment (2nd ed., pp. 3-20). Thousand Oaks, CA: Sage.

[12] Gauthier, L., Stollak, G., Messi, L. \& Aronoff, J. (1996). Recall of childhood neglect and physical abuse as differential predictors of current psychological functioning. Child Abuse \& Neglect, 20, 7, 549-559.

[13] Hartley, C. C. (2002). The co-occurrence of child maltreatment and domestic violence: Examining both neglect and child physical abuse. Child Maltreatment, 7(4), $349-358$.

[14] MacMillan, H. L., Fleming, J. E., Streiner, D. L., Lin, E., Boyle, M., Jamieson, E., Duku, E. K., Walsh, C. A., Wong, M. Y., \& Beardslee, W. R. (2001). Childhood abuse and lifetime psychopathology in a community sample. American Journal of Psychiatry, 158, 1878-1883.

[15] Margolin, G., \& Gordis, E. B. (2003). Co-occurrence between marital aggression and parents' child abuse potential: The impact of cumulative stress. Violence and Victims, 18(3), 243-258. 
[16] McGuigan, W. M., \& Pratt, C. C. (2001). The predictive impact of domestic violence on three types of child maltreatment. Child Abuse \& Neglect, 25, 869-883.

[17] Milner, J. S. (2003). Social information processing in highrisk and physically abusive parents. Child Abuse \& Neglect, 7, 7-20.

[18] Murphy, C. M., \& Cascardi, M. (1999). Psychological abuse in marriage and dating relationships. In R. L. Hampton (Ed.), Family violence prevention and treatment (2nd ed., pp. 198226). Beverly Hills, CA: Sage.

[19] New Jersey Division of Youth and Family Services. (2006). Child abuse and neglect in New Jersey: Statistical report for calendar year 2004. Trenton: New Jersey Department of Children and Families, Division of Youth and Family Services.

[20] Pelaez-Nogueras, M., Gewirtzk, J. L., Field, T., \& Cigales, M. (1996). Infants' preference for touch stimulation in the face-to-face interactions. Journal of Applied Developmental Psychology, 17, $199-213$.

[21] Peters, S., Wyatt, G. E., \& Findelhor, D. (1986) Prevalence. In D. Finkelhor (Ed.). Sourcebook on child sexual abuse (pp. 15 - 59). Beverly Hills, CA: Sage.

[22] Rodriguez, C.M. (2010). Parent-child aggression: Association with child abuse potential and parenting styles. Violence and Victims, 25, 728-741.

[23] Rodriguez, N., Ryan, S.W., Rowan, A.B., \& Foy, D.W. (2006). Post-traumatic stress disorder in a clinical sample of adult survivors of childhood sexual abuse. Child Abuse \& Neglect, 20 (10), 943-952.
[24] Rosenstein, D. S., \& Horowitz, H. A. (1996). Adolescent attachment and psychopathology. Journal of Consulting and Clinical Psychology, 64, 244-253.

[25] Slep, A. M., \& O'Leary, S. G. (2001). Examining partner and child abuse: Are we ready for a more integrated approach to family violence? Clinical Child and Family Psychology Review, 4(2), 87-107.

[26] Straight, E. S., Harper, F.W., \& Arias, I. (2003). The impact of partner psychological abuse on health behaviors and health status in college women. Journal of Interpersonal Violence, 19, 1035-1054.

[27] Street, A. E., \& Arias, I. (2001). Psychological abuse and postraumatic stress disorder in battered women: Examining the roles of shame and guilt. Violence and Victims, 16(1), $65-78$.

[28] U. S. Advisory Board on Child Abuse and Neglect. (1990). Child abuse and neglect: Critical first steps in response to a national emergency. Washington, DC: U.S. Government Printing Office.

[29] Weissman M. M., Orvaschel H, Padian N. (1980). Children's symptom and social functioning self-report scales: Comparison of mothers' and children's reports. Journal of Nervous Mental Disorders 168(12), 736-740.

[30] Widom, C. S. (2000). Understanding the consequences of childhood victimization. In R. M. Reese (Ed.), Treatment of child abuse (pp. 339-361). Baltimore, MD: The Johns Hopkins University Press.

[31] Zlotnick, C., Mattia, J., \& Zimmerman, M. (2001). Clinical features of survivors of sexual abuse with major depression. Child Abuse \& Neglect, 25, 357-367 